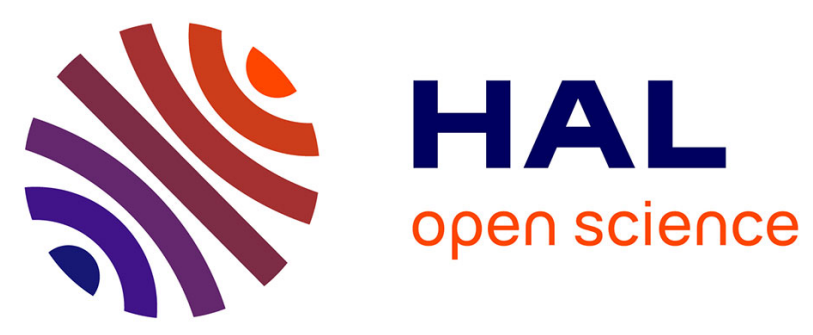

\title{
Dilution effects on ultrafine particle emissions from Euro 5 and Euro 6 diesel and gasoline vehicles
}

Cédric Louis, Yao Liu, Simon Martinet, B d'Anna, Alvaro Martinez Valiente, Antoinette Boreave, Badr R'Mili, Patrick Tassel, Pascal Perret, Michel Andre

\section{- To cite this version:}

Cédric Louis, Yao Liu, Simon Martinet, B d'Anna, Alvaro Martinez Valiente, et al.. Dilution effects on ultrafine particle emissions from Euro 5 and Euro 6 diesel and gasoline vehicles. Atmospheric Environment, 2017, 169, pp.80-88. 10.1016/j.atmosenv.2017.09.007 . hal-01635462

\section{HAL Id: hal-01635462 https://hal.science/hal-01635462}

Submitted on 20 Mar 2019

HAL is a multi-disciplinary open access archive for the deposit and dissemination of scientific research documents, whether they are published or not. The documents may come from teaching and research institutions in France or abroad, or from public or private research centers.
L'archive ouverte pluridisciplinaire HAL, est destinée au dépôt et à la diffusion de documents scientifiques de niveau recherche, publiés ou non, émanant des établissements d'enseignement et de recherche français ou étrangers, des laboratoires publics ou privés. 


\section{Accepted Manuscript}

Dilution effects on ultrafine particle emissions from Euro 5 and Euro 6 diesel and gasoline vehicles

Cédric Louis, Yao Liu, Simon Martinet, Barbara D'Anna, Alvaro Martinez Valiente, Antoinette Boreave, Badr R'Mili, Patrick Tassel, Pascal Perret, Michel André

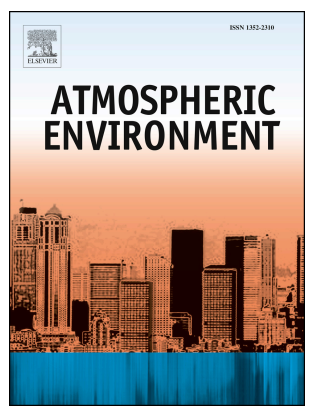

PII:

S1352-2310(17)30589-7

DOI:

10.1016/j.atmosenv.2017.09.007

Reference: $\quad$ AEA 15545

To appear in: Atmospheric Environment

Received Date: 8 March 2017

Revised Date: 22 August 2017

Accepted Date: 3 September 2017

Please cite this article as: Louis, Cé., Liu, Y., Martinet, S., D'Anna, B., Valiente, A.M., Boreave, A., R'Mili, B., Tassel, P., Perret, P., André, M., Dilution effects on ultrafine particle emissions from Euro 5 and Euro 6 diesel and gasoline vehicles, Atmospheric Environment (2017), doi: 10.1016/j.atmosenv.2017.09.007.

This is a PDF file of an unedited manuscript that has been accepted for publication. As a service to our customers we are providing this early version of the manuscript. The manuscript will undergo copyediting, typesetting, and review of the resulting proof before it is published in its final form. Please note that during the production process errors may be discovered which could affect the content, and all legal disclaimers that apply to the journal pertain. 


\title{
Dilution effects on ultrafine particle emissions from Euro 5 and Euro 6 diesel and gasoline vehicles
}

\author{
Cédric Louis ${ }^{\mathrm{a}, \mathrm{b}}$, Yao Liu ${ }^{\mathrm{a}, *}$, Simon Martinet ${ }^{\mathrm{a}}$, Barbara D’Anna ${ }^{\mathrm{c}}$, Alvaro Martinez Valiente ${ }^{\mathrm{c}}$, \\ Antoinette Boreave ${ }^{\mathrm{c}}$, Badr R'Mili ${ }^{\mathrm{c}}$, Patrick Tassel ${ }^{\mathrm{a}}$, Pascal Perret ${ }^{\mathrm{a}}$, Michel André ${ }^{\mathrm{a}}$ \\ ${ }^{a}$ Univ Lyon, IFSTTAR, AME, LTE, F-69675, LYON, France \\ ${ }^{\mathrm{b}}$ French Environment and Energy Management Agency, ADEME, 49004 Angers, France \\ c IRCELYON - UMR 5256 CNRS - Université de Lyon, 69626 Villeurbanne, France \\ * Corresponding author: yao.liu@ ifsttar.fr, 25 avenue François Mitterrand, 69675 Bron, France
}

\begin{abstract}
Dilution and temperature used during sampling of vehicle exhaust can modify particle number concentration and size distribution. Two experiments were performed on a chassis dynamometer to assess exhaust dilution and temperature on particle number and particle size distribution for Euro 5 and Euro 6 vehicles. In the first experiment, the effects of dilution (ratio from 8 to 4000) and temperature (ranging from $50{ }^{\circ} \mathrm{C}$ to $150{ }^{\circ} \mathrm{C}$ ) on particle quantification were investigated directly from tailpipe for a diesel and a gasoline Euro 5 vehicles. In the second experiment, particle emissions from Euro 6 diesel and gasoline vehicles directly sampled from the tailpipe were compared to the constant volume sampling (CVS) measurements under similar sampling conditions. Low primary dilutions (35) induced an increase in particle number concentration by a factor of 2 compared to high primary dilutions (12-20). Low dilution temperatures $\left(50{ }^{\circ} \mathrm{C}\right)$ induced $1.4-3$ times higher particle number concentration than high dilution temperatures $\left(150^{\circ} \mathrm{C}\right)$. For the Euro 6 gasoline vehicle with direct injection, constant volume sampling (CVS) particle number concentrations were higher than after the tailpipe by a factor of 6,80 and 22 for Artemis urban, road and motorway, respectively. For the same vehicle, particle size distribution measured after the tailpipe was centred on $10 \mathrm{~nm}$, and particles were smaller than the ones measured after CVS that was centred between $50 \mathrm{~nm}$ and $70 \mathrm{~nm}$. The high particle concentration $\left(\approx 10^{6} \# / \mathrm{cm}^{3}\right)$ and the growth of diameter, measured in the CVS, highlighted aerosol transformations, such as nucleation, condensation and coagulation occurring in the sampling system and this might have biased the particle measurements.
\end{abstract}

\section{Keywords}

Gasoline and diesel emissions; CVS; Tailpipe; Dilution; Temperature; Ultrafine particle; Nucleation; Condensation; Coagulation

\section{Abbreviations}

G-DI Gasoline with Direct Injection

cat Catalysed Filter

CVS Constant Volume Sampler

$\mathrm{NO}_{\mathrm{X}} \quad$ Nitrogen Oxides

NO Nitric Oxide

CPC Condensation Particle Counter

SMPS Scanning Mobility Particle Sizer

HEPA high-efficiency particulate air
DPF Diesel Particulate Filter

PMP Particle Measurement Programme

FPS Fine Particle Sampler

$\mathrm{NO}_{2} \quad$ Nitrogen Dioxide

PN Particle Number

ELPI Electrical Low Pressure Impactor

FMPS Fast Mobility Particle Sizer Spectrometer 


\section{Introduction}

Vehicle exhaust emissions represent a major source of particle matter in urban environments. On regional and global scales, atmospheric particles play an important role in human health and climate change (Ning, 2010; Kulmala et al., 2000; Pope III, 2000). Particles emitted from diesel and gasoline engines are ultrafine particles with size ranges of 20-130 nm and 20-60 nm, respectively (Karjalainen et al., 2014; Morawska et al., 2008; Burtscher 2005; Jamriska et al., 2004). The ultrafine particles represent only $0.1-10 \%$ of the total particulate mass, but it might represent more than $90 \%$ of the total particle number (Giechaskiel et al., 2010; Kittelson, 1998). Particle emission depends on the engine technology, fuel and aftertreatment devices. Liang et al. (2013) and Köhler (2013) showed that the gasoline direct injection (G-DI) technology induced an increase in the particle number concentration compared to the standard gasoline passenger cars. Moreover, the dilution process (dilution ratio, dilution gas temperature and sampling residence time) has been established as a factor influencing ultrafine particle formation (Manoukian et al., 2016; Wei et al., 2016; Ranjan et al., 2012; Fujitani et al., 2012; Mamakos and Martini, 2011; Grieshop et al., 2009a; Vouitsis et al., 2008; Rönkkö et al., 2006; Mathis et al. 2004). After the tailpipe, the exhaust undergoes high and fast atmospheric dilution ratio that could reach up from 1000 to 4000 in 1-3 s (Fujitani et al., 2012; Zhang and Wexler, 2004). The exhaust temperature (around $200{ }^{\circ} \mathrm{C}$ ) decreases rapidly at ambient temperature level within few seconds after emission due to the high dilution ratio. The rapid decrease in temperature has significant implications in terms of thermodynamics of particles and semi-volatile compounds (Kim et al., 2016; Huang et al., 2014; May et al., 2013; Wang and Zhang, 2012; Kozawa et al., 2012; Mamakos and Martini, 2011; Casati et al., 2007; Morawska et al., 2008; Zhang et al., 2004) leading to a drastic change in particle number concentration and size distribution (Huang et al., 2014; Wang and Zhang, 2012; Uhrner et al., 2011; Grieshop 2009b). Although several recent studies have focused on that issue, uncertainties still remain regarding the experimental determination of ultrafine particle emissions from vehicle exhaust and the impact of dilution and temperature during their sampling (Wei et al., 2016; Manoukian et al., 2016; Ranjan et al., 2012; Fujitani et al., 2012; Grieshop et al., 2009a).

Particle number concentration is measured through a specific protocol, derived from the Particle Measurement Program (PMP) through the full-flow Constant Volume Sampler (CVS). This protocol requires the removal of the volatile phase by the dilution stage $\left(150{ }^{\circ} \mathrm{C}\right)$ and a heated tube (at $300-400{ }^{\circ} \mathrm{C}$ ). The PMP approach only regulates the non-volatile fraction of particles in order to exclude the possible confounding of measurement data by low volatility hydrocarbons manifesting as a nucleation mode present below $20 \mathrm{~nm}$ that highly depends on the sampling conditions (Giechaskiel et al., 2008). In the atmosphere, the concentration of aerosols changes rapidly in the first seconds after emission with condensation phenomenon and presence of SVOCs, which strongly depend on the exhaust sampling (length of the sampling line, dilution factor, temperature, etc.) (Albriet et al., 2010). Several studies showed that the ultrafine particle number concentration directly measured from the tailpipe was significantly different than those from the CVS (Kim et al., 2016; Giechaskiel et al., 2010, 2007; Mathis et al., 2005). Giechaskiel et al. (2010) showed that deceleration (from $140 \mathrm{~km} / \mathrm{h}$ to 120 $\mathrm{km} / \mathrm{h}$ ) induced a higher particle number concentration with higher mean diameter than acceleration (from $90 \mathrm{~km} / \mathrm{h}$ to $120 \mathrm{~km} / \mathrm{h}$ ) with a Euro 3 diesel vehicle without particulate filter. This observation is in contrast with their previous work (Giechaskiel et al., 2007), which reported a lower particle number concentration during deceleration than during acceleration. This contradiction can be explained by differences in sampling systems. According to Giechaskiel et al. (2007), particles were sampled directly from the tailpipe, while in Giechaskiel et al. (2010), particles were sampled from the CVS. As mentioned by Giechaskiel et al. (2014), the CVS dilution tunnel has several disadvantages such as the inability to control the dilution ratio and the dilution temperature, a long sampling path and a long 
residence time. This dilution system favours nucleation, condensation and coagulation that could induce the new particle formation or the modification of the particle size distribution.

Based on this evidence, the particle measurement directly from the tailpipe was considered as a complementary sampling method to CVS in order to understand the sampling condition impacts on particle number concentration. This work aimed to investigate the impacts of dilution and temperature on particle emissions after a CVS tunnel system and directly from the tailpipe with Euro 5 and Euro 6 vehicles. Particle number and size distribution between the CVS and the tailpipe were compared under similar dilution conditions to investigate the processes occurring in the dilution tunnel with the Euro 6 G-DI vehicle. Finally, we discussed the nucleation, condensation and coagulation phenomena observed into the CVS dilution system. 


\section{Materials and methods}

106

\subsection{Vehicle characteristics}

Four currently in-use vehicles were studied: a Euro 5 gasoline with direct injection system (GDI), and Euro 5 diesel with catalysed particulate filter (DPF cat), a Euro 6 G-DI and a Euro 6 DPF cat. Technical characteristics of the tested vehicles are shown in Table 1. All the tested vehicles were private vehicles to be as representative as possible of the state of the current French fleet. All experiments were conducted using commercial fuel (sulphur content less than $10 \mathrm{ppm}$ ) pumped from the same petrol station to minimize variability of fuel composition and its impact on emissions.

Table 1. Technical characteristics of the tested vehicles.

\begin{tabular}{lllll}
\hline Vehicle & No. 1 & No. 2 & No. 3 & No. 4 \\
\hline Size class & 1.2 & 1.5 & 1.0 & 1.5 \\
Technology & G-DI* & Diesel & G-DI* & Diesel \\
Standard & Euro5 & Euro5 & Euro 6 & Euro 6 \\
Empty weight (kg) & 1320 & 1090 & 864 & 1087 \\
Mileage (km) & 25844 & 87073 & 2164 & 4700 \\
Gearbox type & Manual (5) & Manual (5) & Manual (5) & Manual (5) \\
Registration date & $27 / 02 / 2014$ & $17 / 02 / 2012$ & $11 / 12 / 2015$ & $31 / 12 / 2015$ \\
Test date & $31 / 03 / 2015$ & $15 / 04 / 2015$ & $29 / 03 / 2016$ & $11 / 04 / 2016$ \\
Catalyst & Three-way & Oxidation & Three-way & Oxidation \\
Filter & No & Catalysed DPF & No & Catalysed DPF \\
\hline
\end{tabular}

* G-DI: Gasoline with direct injection system

${ }^{\$}$ DPF: Diesel Particulate Filter

\section{$2.2 \quad$ Experimental set-up}

Emission measurements were performed on the chassis dynamometer at the Transports and Environment Laboratory (LTE) of the French Institute of Science and Technology for Transport, Development and Networks (IFSTTAR). The chassis dynamometer was composed of a 48-inch roller on which the drive wheels of the vehicle were placed. The dynamometer resisted to the vehicle rolling to simulate the road resistance, which was calculated based on road laws for each vehicle. The schema of the experimental setup is shown in Figure 1. Vehicle exhausts were sampled through two different ways: one directly at the tailpipe, diluted by the fine particle sampler (FPS) and the other through the CVS. Exhaust sampling from these two systems was diluted with filtered ambient air system. 


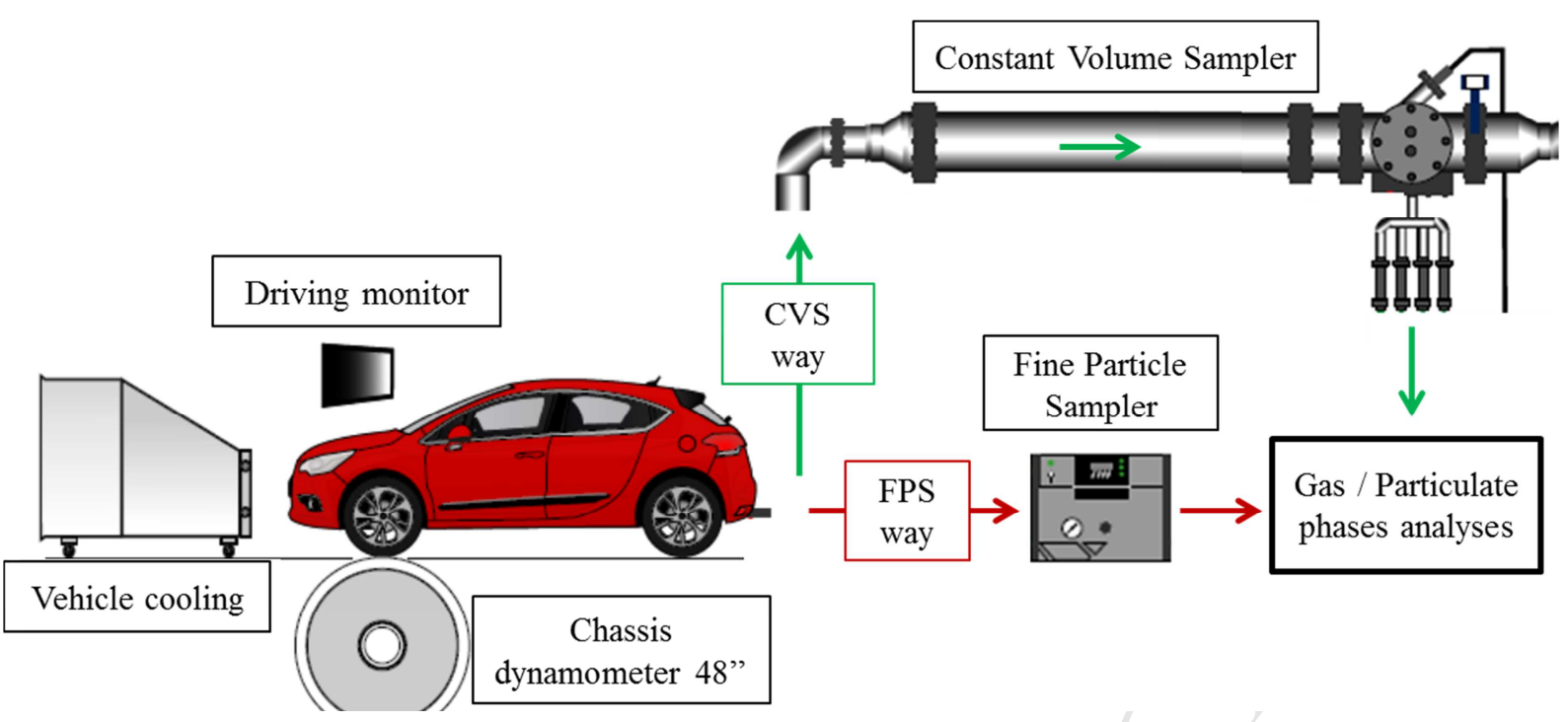

Figure 1. Schema of the experimental setup; the green arrows represent the CVS way and the red arrows represent the direct tailpipe way with FPS dilution.

\subsubsection{Dilution systems}

- Constant Volume Sampler (CVS)

Exhaust emissions measured using a CVS system were diluted with filtered ambient air (4 filters in series including M6-F7-F9, M5, F7 EN-779-2012 filters, a HEPA H13 EN1822-2009 filter and a cylindrical cartridge of charcoal scrubber). This filtered air allowed compensating the flow rate variations related to the exhaust flow fluctuations and keeping a constant volume sampling. The mixture air/exhaust went through the dilution tunnel, and then was monitored by different on-line gas and particulate phase analysers.

\section{- Fine Particle Sampler (FPS)}

A Fine Particle Sampler (FPS 4000, Dekati Ltd) was used for direct tailpipe dilution. The exhaust dilution was carried out in two stages: a primary dilution, close to the sampling point with controlled temperature and a secondary dilution as ejector type diluter, located downstream of the primary dilution and which adjusted the primary dilution to provide the total dilution. The FPS enabled the control of several dilution parameters such as sampling flow, primary dilution, total dilution and temperature.

\subsubsection{Experimental protocol}

Dilution and temperature effects were studied with two Euro 5 vehicles: gasoline (No. 1) and diesel (No. 2). The vehicles were tested with two Artemis cycles (motorway and urban) (André, 2004) and at $70 \mathrm{~km} / \mathrm{h}$ steady speed. The particles were sampled from the tailpipe after the FPS dilution with or without VKL dilutors (depending on the total dilution tested). The FPS dilution temperatures were set at $50^{\circ} \mathrm{C}, 100^{\circ} \mathrm{C}$, and $150^{\circ} \mathrm{C}$ and the total dilution ratios were $30,100,400,1000,2000$ and 4000 for gasoline and 8, 12, 16, 30, 100, 400, 1000, 2000, 4000 for diesel. Each experimental condition was repeated three times.

To compare the tailpipe emissions with the CVS measurements, the Euro 6 gasoline (No.3) and the diesel (No.4) vehicles were tested with Artemis road, motorway and urban driving conditions. The detailed driving cycles with repeated tests and sampling conditions were shown in Table 2 . The CVS operated at a total flow rate of $11 \mathrm{~m}^{3} / \mathrm{min}$ for the Artemis motorway cycle and $9 \mathrm{~m}^{3} / \mathrm{min}$ for the other driving cycles. The average CVS dilution ratios ranged between 13 and 60 for the gasoline vehicle and between 22 and 77 for the diesel vehicle, with a dilution temperature at $35{ }^{\circ} \mathrm{C}$. At the 
tailpipe the FPS primary dilution was set at $36^{\circ} \mathrm{C}$ to reproduce similar dilution and temperature conditions as in the CVS.

Table 2. Detailed driving cycles with test number and sampling conditions for the FPS and the CVS with Euro 6 G-DI (No.3) and Euro 6 diesel DPF cat (No.4) vehicles.

\begin{tabular}{lcccccccc}
\hline Vehicles & \multicolumn{3}{c}{ Euro 6 G-DI (No. 3) } & \multicolumn{3}{c}{ Euro 6 diesel DPF cat (No. 4) } \\
\hline $\begin{array}{l}\text { Artemis } \\
\text { cycles }\end{array}$ & $\begin{array}{c}\text { Repeated } \\
\text { number }\end{array}$ & $\begin{array}{c}\text { CVS } \\
\text { dilution }\end{array}$ & $\begin{array}{c}\text { Total } \\
\text { tailpipe } \\
\text { dilution }\end{array}$ & $\begin{array}{c}\text { Primary } \\
\text { dilution }\end{array}$ & $\begin{array}{c}\text { Repeated } \\
\text { number }\end{array}$ & $\begin{array}{c}\text { CVS } \\
\text { dilution }\end{array}$ & $\begin{array}{c}\text { Total } \\
\text { tailpipe } \\
\text { dilution }\end{array}$ & $\begin{array}{c}\text { Primary } \\
\text { dilution }\end{array}$ \\
\hline Road & 9 & 33 & 35 & 22 & 9 & 51 & 54 & 25 \\
Urban & 10 & 60 & 59 & 25 & 10 & 77 & 88 & 27 \\
Motorway & 6 & 13 & 15 & 12 & 6 & 22 & 18 & 17 \\
\hline
\end{tabular}

\section{3}

\subsection{Analytical methods}

\subsubsection{Regulated compound analysis}

Regulated compounds, such as carbon oxide $(\mathrm{CO})$, carbon dioxide $\left(\mathrm{CO}_{2}\right)$, total hydrocarbons (THC), nitric oxide $(\mathrm{NO})$ and nitrogen oxides $\left(\mathrm{NO}_{\mathrm{x}}\right)$ were monitored using a Horiba emission measurement system ( $\mathrm{CO}$ and $\mathrm{CO}_{2}$ by non-dispersive infrared, THC by flame ionization detection, $\mathrm{NO}$ and $\mathrm{NO}_{\mathrm{X}}$ by chemiluminescence). The $\mathrm{NO}_{2}$ concentration was determined by subtracting $\mathrm{NO}$ from $\mathrm{NO}_{\mathrm{X}}$. Regulated compounds were monitored to ensure that vehicles had regular emission behaviours with respect to their category and to detect any abnormalities that could introduce bias in the measurements.

\subsubsection{Particulate phase analysis}

The particle number concentration and the size distribution were measured by a Fast Mobility Particle Sizer Spectrometer (FMPS, model 3091 TSI). Particles went through a cyclone with a $1 \mu \mathrm{m}$ cut off and an electrical diffusion charger. The particle number concentration from $5.6 \mathrm{~nm}$ to $560 \mathrm{~nm}$ is determined by measuring the electrical current collected on a series of electrodes. Data were collected every second at $8 \mathrm{~L} / \mathrm{min}$. The quantification limit depended on the particle size: for $5.6 \mathrm{~nm}$ the maximum limit was $10^{7} \# / \mathrm{cm}^{3}$ and the minimum limit was $100 \mathrm{\#} / \mathrm{cm}^{3}$. Particle size number distribution was also characterised using an Electrical Low Pressure Impactor (ELPI, Dekati). The ELPI measured the particle number distribution in the $7 \mathrm{~nm}$ to $4 \mu \mathrm{m}$ range with 12 filter stages. The operating flow rate of the ELPI was set at $10 \mathrm{~L} / \mathrm{min}$ with a sampling period of $1 \mathrm{~s}$. The quantification limits ranged from 250 to $7 \times 10^{7} \# / \mathrm{cm}^{3}$ for particles with a diameter between $7 \mathrm{~nm}$ and $4 \mu \mathrm{m}$ and from 0.1 to $2 \times 10^{4}$ $\# / \mathrm{cm}^{3}$ for particles with a diameter greater than $4 \mu \mathrm{m}$. A Condensation Particle Counter (CPC, model 3775 TSI) was used for total particle number concentration. The CPC contained a butanol condensation chamber that enabled the detection of particles greater than $4 \mathrm{~nm}$ (particle size cut 50\%). The operating flow rate of CPC was set at $1.5 \mathrm{~L} / \mathrm{min}$. The experimental data were collected every second with a concentration ranging from 0 to $10^{7} \mathrm{\#} / \mathrm{cm}^{3}$.

The Particle Measurement Programme has been proposed as a regulatory approach for measuring particle numbers for Euro 5 and Euro 6 vehicles, with a 50\% cut-point size of $23 \mathrm{~nm}$. However, most particles emitted by the tested vehicles in our previous experiments were ultrafine particles with diameters below $23 \mathrm{~nm}$, especially during the Artemis motorway driving cycle and 
182 particulate filter regeneration (Louis et al., 2016). In order to have the most complete information on 183 total particle number emissions including particles smaller than $23 \mathrm{~nm}$, and to compare it with direct 184 tailpipe emission, we did not fully follow the PMP protocol in this study. However the CVS tunnel 185 was conditioned according the latest regulatory requirement in Europe with heated air dilution at $18635^{\circ} \mathrm{C}$. Furthermore, by considering the volatile fraction of particles, the standard variations of particle 187 number concentration with six repeated tests, ranged from 7 to $11 \%$. 


\section{Results and discussion}

\subsection{Dilution and temperature effects}

For the Euro 5 gasoline vehicle, the exhaust was sampled directly from the tailpipe at different total dilution ratios through the FPS (at 30, 100, 400, 1000, 2000 and 4000). The total dilution ratios at 30, 400, 2000 and 4000 were obtained with low primary dilution ratios between 3 and 5, while the total dilution at 100 and 1000 were obtained with high primary dilution ratios between 12 and 20 . Figure $2 \mathrm{a}$ showed the particle number concentration with the total dilution ratios between 30 and 4000 as function of the dilution temperature at 50,100 and $150{ }^{\circ} \mathrm{C}$ during motorway driving condition. We observed that the temperature played an important role on particle concentrations. According to Beckers et al. (2009), low temperature $\left(50{ }^{\circ} \mathrm{C}\right)$ induced 1.4 to 3 times more PN than high temperature $\left(150{ }^{\circ} \mathrm{C}\right)$ for all tested dilution ratios. The PN concentrations were classified into two groups: black dots for total dilution of 30, 400, 2000 and 4000 characterized by a low primary dilution (3-5); white empty dots for the total dilution at 100, 1000 with high primary dilution (12-20). These latter total dilutions induced less particle emissions than dilution at 30, 400, 2000 and 4000 (Figure 2a). This can be explained by the fact that dilution ratios 100 and 1000 were achieved using high primary dilution ratio and it emphasised the key role of the primary dilution ratio. Figure $2 b$ showed the particle number emissions from a gasoline vehicle as function of the primary dilution (3-20) under motorway driving condition with three primary dilution temperatures $\left(50,100\right.$ and $\left.150^{\circ} \mathrm{C}\right)$. The particle number concentration was corrected taking into account the dilution factors. At low primary dilution (3-5) with the three tested dilution temperatures, PN concentrations were at $2-3 \times 10^{7} \# / \mathrm{cm}^{3}$. For these sampling conditions, PN concentration did not depend on the dilution gas temperature. At high primary dilution conditions (12-20), PN concentration decreased with the increase in temperature. PN emissions were about 2 times lower (at $1-1.5 \times 10^{7} \# / \mathrm{cm}^{3}$ ) at $100^{\circ} \mathrm{C}$ and $150^{\circ} \mathrm{C}$ than at $50^{\circ} \mathrm{C}$. For the same temperature at 100 and $150{ }^{\circ} \mathrm{C}$, the $\mathrm{PN}$ concentration decreased with the increase in the primary dilution ratio. These results were in agreement with the ones reported by Casati et al. (2007) for Euro3 diesel passenger cars. Their results indicated that the low primary dilution and the low dilution temperature of gas might promote the measurement bias. They recommended setting the sampling system at a high primary dilution and high dilution temperature to minimise those bias. For the Euro 5 diesel vehicle, PN emissions were low due to the high filtration efficiency of the diesel particulate filter (DPF). The particle number concentrations were lower than the detection limit of the instrument for most of the dilution conditions and were not presented. 
(a) Total dilution and temperature effect

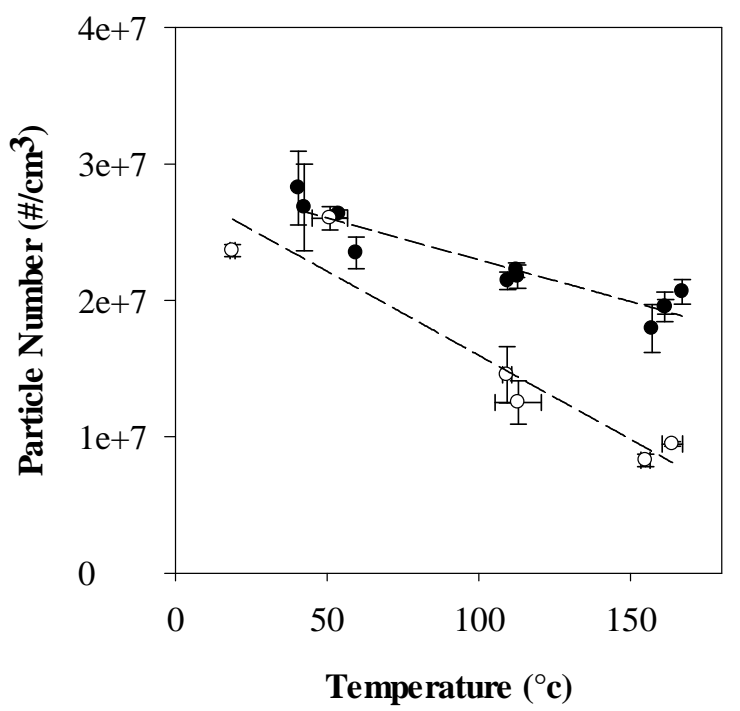

(b) Primary dilution and temperature effect

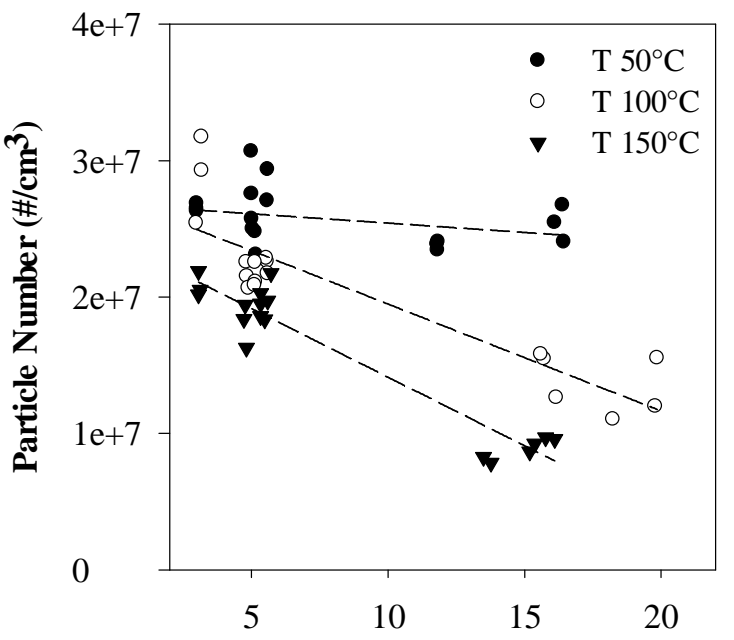

Primary Dilution Ratio

- Dilutions 30, 400, 2000 and 4000 with low primary dilution (3-5)

- Dilutions 100 and 1000 with high primary dilution (12-20)

Figure 2. Total dilution and temperature effects (a) and primary dilution and temperature effects (b) for the gasoline Euro 5 vehicle (No. 1) during the motorway driving conditions, at $50^{\circ} \mathrm{C}, 100^{\circ} \mathrm{C}$ and $150^{\circ} \mathrm{C}$. The particle number emissions are corrected taking into account of the dilution factors. For the figure $2 \mathrm{a}$, the black dots show total dilution ratios at 30, 400, 2000 and 4000 with low primary dilution (3-5) and the white dots show total dilution ratios at 100 and 1000 with high primary dilution (12-20).

\subsection{Euro 6 G-DI particle characterisation tailpipe / CVS}

PN emissions measured from the tailpipe have also been compared with CVS measurements for two Euro 5 vehicles under Artemis motorway cycle. Statistically significant differences in PN concentration have been observed between these two sampling systems. Particle size distribution was unimodal and centred at $20 \mathrm{~nm}$ after the tailpipe (FPS sampling system) and at more than $60 \mathrm{~nm}$ after the CVS. However, different analysers have been used for the PN quantification at the tailpipe (with an ELPI) and after the CVS (with a SMPS) due to experimental organisation and constraints. Therefore, in order to better understand the physical processes occurring in the sampling systems, with their impact on PN measurement, two Euro 6 gasoline and diesel vehicles have been tested. The PN concentrations have been followed by a FMPS after the tailpipe and after the CVS with Artemis Urban, Road and Motorway cycles. Primary dilution at 20 was chosen to the tailpipe dilution in order to minimise the PN concentration measurement bias.

\subsubsection{Particle concentration comparison between tailpipe and CVS}

Due to the high efficiency of the diesel particulate filter, PN emission from the Euro 6 diesel vehicle was lower than the analyser detection limit. Therefore, only gasoline emissions were presented and discussed here. Table 3 showed the average particle number concentrations for Euro 6 gasoline GDI for the Artemis urban, road and motorway driving cycles. The concentrations reported were average values of several repeated cycles for each driving condition. The PN measurement after CVS and tailpipe were performed under similar total dilution and temperature conditions (Table 2). PN concentrations from CVS were higher than at tailpipe by a factor of 6, 80 and 22 for Artemis urban, road and motorway, respectively. Highest discrepancies were observed under Artemis road cycle. Unfortunately, we did not find an explication, since the tests were repeated 5 and 3 times after CVS and exhaust, respectively, which showed similar result. 
Table 3. Average particle number concentration for G-DI Euro 6 vehicle.

\section{Particle concentration $\left(\# / \mathrm{cm}^{3}\right)$ G-DI Euro 6}

\begin{tabular}{|c|c|c|c|c|c|}
\hline Driving cycle & Start & CVS & $\begin{array}{l}\text { Tests } \\
\text { Number }\end{array}$ & Exhaust & $\begin{array}{l}\text { Tests } \\
\text { Number }\end{array}$ \\
\hline Artemis urban & hot start & $(9 \pm 5) \times 10^{4}$ & 7 & $(1.4 \pm 0.6) \times 10^{4}$ & 3 \\
\hline Artemis & hot start & $(2.3 \pm 0.4) \times 10^{6}$ & 5 & $(3 \pm 2) \times 10^{4}$ & 3 \\
\hline Artemis motorway & hot start & $(2.2 \pm 0.1) \times 10^{7}$ & 3 & $(1.0 \pm 0.3) \times 10^{6}$ & 3 \\
\hline
\end{tabular}

\subsubsection{Particle size distribution comparison between the tailpipe and the CVS}

Figure 3 showed the particle number concentration and size distribution as a function of cycle time for the Euro 6 G-DI vehicle during an Artemis motorway driving cycle after the tailpipe (Figure 3a) and after the CVS (Figure 3b). At the tailpipe, particle emissions were characterised by narrow peaks of about $5 \mathrm{~s}$ mainly during accelerations (Figure 3a), while after CVS particle emissions were characterised by larger emission peaks of about 30s and were observed for the whole cycle length (Figure 3b). Particle size distribution after tailpipe varied between $2 \mathrm{~nm}$ and $70 \mathrm{~nm}$ with a main mode at $10 \mathrm{~nm}$. After the CVS the particle size distribution was centred at $50 \mathrm{~nm}$ and no particles below 30 $\mathrm{nm}$ were detected. This observation indicated that condensation and possibly coagulation happened. We observed an increase in PN after the CVS suggesting that also nucleation occurred in the CVS tunnel.
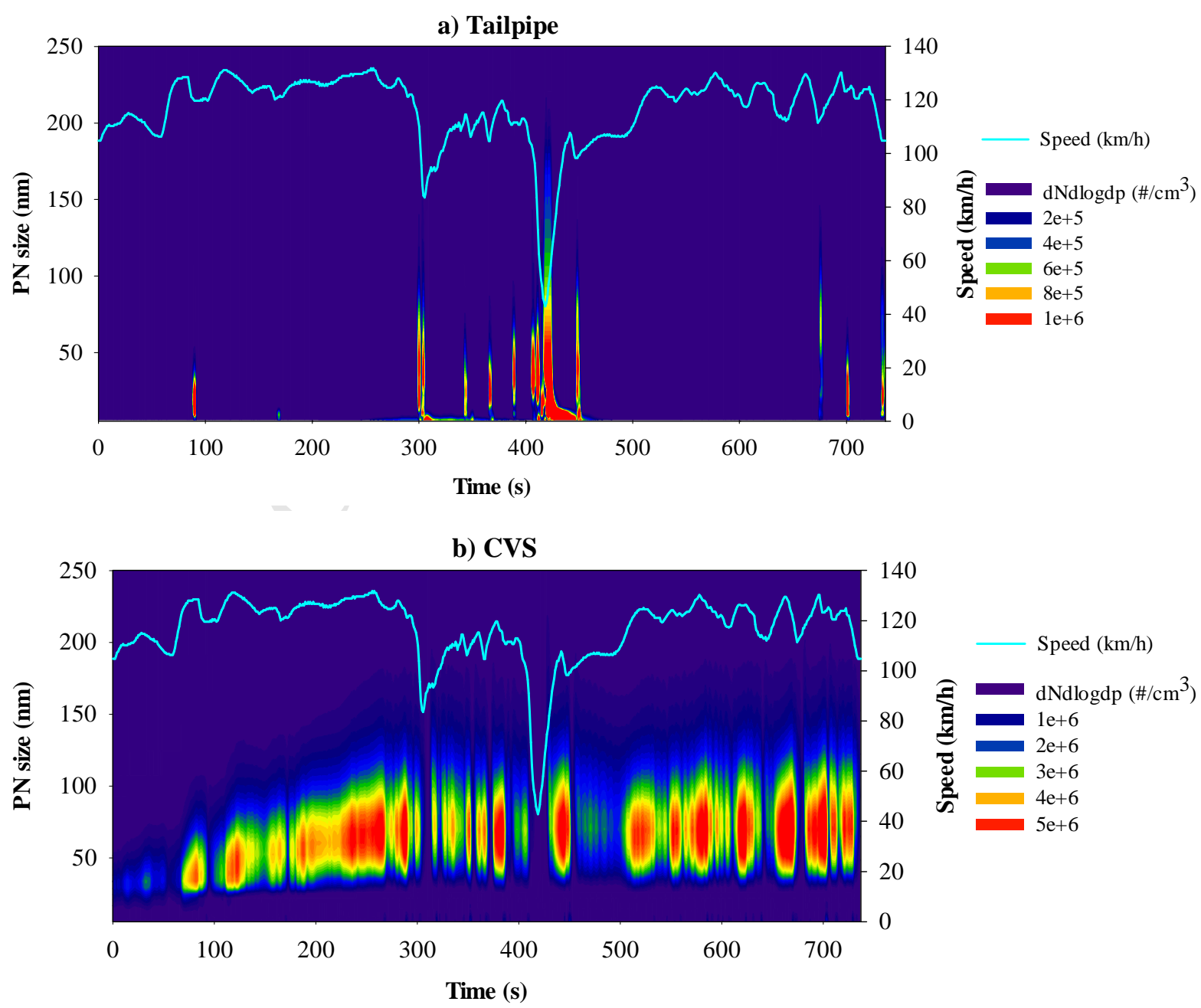
Figure 3. Particle number concentration of the G-DI vehicle during an Artemis motorway driving cycle, sampled: a) after the tailpipe and b) after the CVS. PN size distribution is described on the left $\mathrm{Y}$-axis. The light blue line represents the vehicle speed $(\mathrm{km} / \mathrm{h})$ on the right $\mathrm{Y}$-axis.

Vehicle accelerations lead to distinct emission peaks. An average of emissions over the whole cycle did not account for these disparities. In order to compare the CVS and exhaust particle size in an acceleration phase (high emission), we choose the highest emission peak for each cycle. Comparisons were made at 500s, 750s and 430s, respectively, for Artemis urban, road and motorway cycles. Figure 4 showed the PN size distribution for these three driving conditions after the tailpipe (Figure 4a) and after the CVS (Figure 4b). For motorway, both tailpipe and CVS particle size distribution were unimodal. However, the CVS measurement showed a higher PN concentration with the particle diameter centred at $70 \mathrm{~nm}$ comparing to the tailpipe, for which the particle diameter was smaller and centred at $10 \mathrm{~nm}$. For urban, particle size distribution after the tailpipe was similar than the motorway cycle, with a unimodal distribution centred at $10 \mathrm{~nm}$. While after the CVS, the PN size distribution was bimodal with a main mode at $50 \mathrm{~nm}$ and a second lower mode at $10 \mathrm{~nm}$. For road, the tailpipe particle size distribution was different than motorway and urban. It showed a bimodal distribution with two main modes at $10 \mathrm{~nm}$ and $30 \mathrm{~nm}$, and the CVS particle size distribution was unimodal and centred at $50 \mathrm{~nm}$. However, a similar increase in the particle diameter and concentration was observed in the CVS as two other driving conditions. This observation could be explained by the nucleation, condensation and coagulation phenomena as described by Seinfeld (2016). The increase in particle number highlighted that nucleation process happened in the CVS. Moreover, different precursors in vehicle exhaust, such as semi volatile compounds, sulfuric acid, ammonia, polycyclic aromatic hydrocarbons (PAH), hopanes and steranes, could cause the nucleation and induce an increase in small particle numbers (Louis et al., 2016; Benson et al., 2011; Casati et al., 2007; Virtanen et al., 2006; Burtscher, 2005; Mathis et al., 2005; Zielinska et al., 2004; Bukowiecki et al., 2003). The nucleation phenomenon has already been observed in other exhaust dilution studies by Vouitsis et al. (2009) and Kittelson et al. (1998 and 2000). On the other hand, the particle growth from $10 \mathrm{~nm}$ to $50 \mathrm{~nm}$ highlighted the condensation and coagulation phenomena that depended on the SVOCs and particle concentration in the exhaust. The SVOCs condensed to the particle surface as function of the partition coefficient between the gas and the particulate phase, which induced a rapid growth of the particles (Zhang et al., 2004). The work of Albriet et al. (2010), with an aerosol computational fluid dynamics model (CFD), confirmed that SVOCs condensation governed the growth of the nanoparticles in the tailpipe plume of vehicles. 
a) Tailpipe

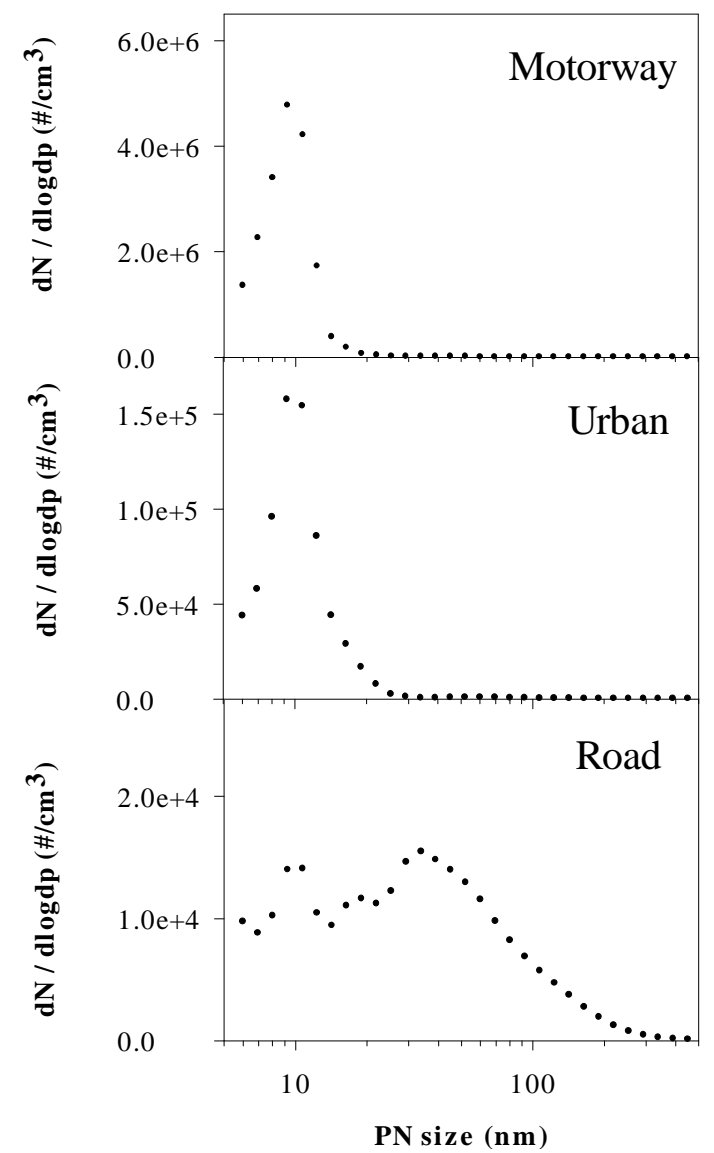

b) CVS

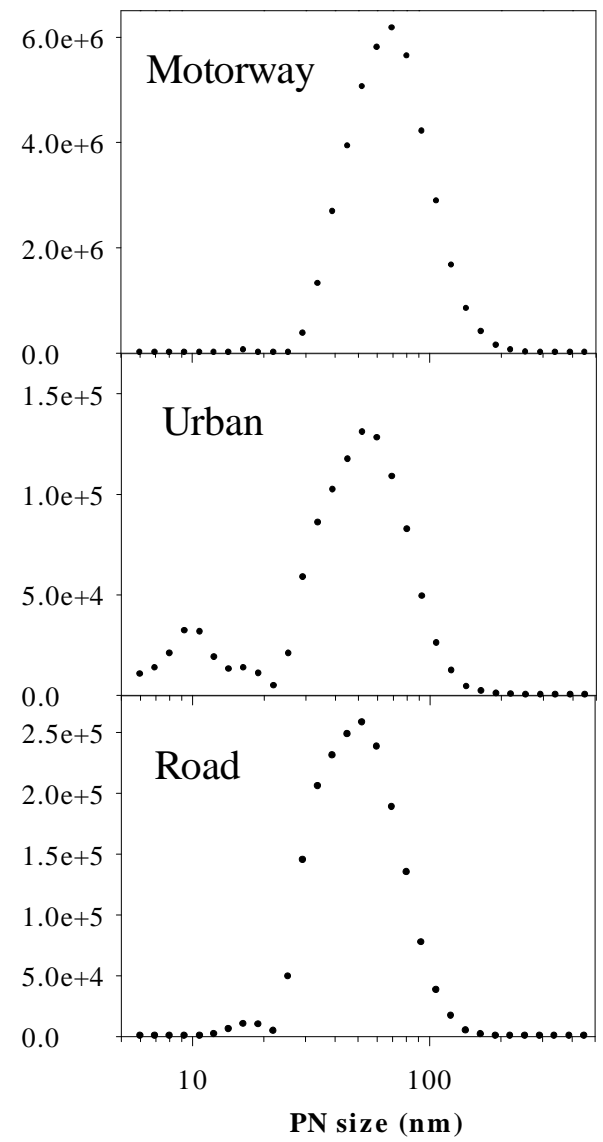

Figure 4. Euro 6 G-DI particle size distribution: a) after tailpipe and b) after CVS for Artemis motorway (at 430s), urban (at 500s) and road (at 750s). Data were measured by a Fast Mobility Particle Sizer Spectrometer (FMPS).

For urban, we also observed a particle mode at $10 \mathrm{~nm}$ after CVS that could be explained by the lower PN concentration and flow rate in the CVS than motorway $\left(9 \mathrm{~m}^{3} / \mathrm{min}\right.$ for urban and $11 \mathrm{~m}^{3} / \mathrm{min}$ for motorway). According to Albriet et al. (2010), turbulence remains a crucial parameter for particle growth. The CVS sampling system turbulence was calculated by the Reynolds number given by Kulkarni (2011). Reynolds number determines if the gas flow was laminar $\left(\operatorname{Re}<3 \times 10^{3}\right)$ or turbulent $\left(\operatorname{Re}>3 \times 10^{3}\right)$.

$$
R e=\frac{U \times d}{v}
$$

U: velocity characteristic of the gas $(\mathrm{m} / \mathrm{s})$ $\mathrm{d}$ : diameter of the pipe (m)

$308 v$ : kinematic gas viscosity $\left(v=\mathrm{y} / \rho_{g}\right)$

For the CVS sampling system, the Reynolds numbers were $5 \times 10^{4}, 4 \times 10^{4}$ and $4 \times 10^{4}$ for the motorway, urban and road cycles respectively that were greater than the limit value $\left(3 \times 10^{3}\right)$. The CVS flow was thus a turbulent flow that promoted the phenomena of condensation and coagulation as well as the temporal diffusion of the PN concentration peaks. This turbulence was proportional to the average cycle speed. Low turbulence for the urban condition together with low PN concentration induced low coagulation and condensation rates compared to motorway condition, which could explain the bimodal PN distribution in the CVS. 
Furthermore, high particle concentration and turbulent flow added to the Brownian motion (random movement of a particle due to collisions with surrounding air particles) could induce turbulent coagulation (Huang et al., 2014; Zhang et al., 2004). Table 4 (Appendix) shows an example of particle coagulation time with different particle sizes and particle concentrations. The coagulation coefficients used in this work were taken from Seinfeld (2016) assuming that the particles were monodisperse taken into account the kinetic corrections and without turbulence. The coagulation halflife time $\left(\tau_{c}\right)$ was determined with the following equation:

$$
\tau_{c}=\frac{2}{K \times N_{0}}
$$

$\mathrm{K}$ : coagulation coefficient for monodisperse aerosols;

For particles having mobility diameter at $10 \mathrm{~nm}$, the coagulation times were 3,100 and 1000 minutes (Table 4, Appendix) for the concentration at $5.5 \times 10^{6} \# / \mathrm{cm}^{3}, 1.6 \times 10^{5} \# / \mathrm{cm}^{3}$ and $1.4 \times 10^{4} \# / \mathrm{cm}^{3}$, respectively, which represented motorway, urban and road PN emissions (Figure 4). For the particles with diameter at $40 \mathrm{~nm}$, the coagulation times were higher than 1000 minutes for all conditions. According to Albriet et al. (2010) and Grieshop et al. (2009a), coagulation by diffusion is a slow process that takes more than five minutes to occur, which is greater than the CVS residence time (2-10 seconds). The turbulence of gas flow in the sampling system could reduce the coagulation time. However, coagulation is known to have a little impact on particle growth in the first seconds after the exhaust (Albriet et al., 2010). These results indicated that the CVS sampling system could induce nucleation and condensation phenomena influencing the particle characteristic and quantification.

335 Particle sampling at the tailpipe could represent a complementary method to better quantify the 336 particle emissions. 


\section{Conclusion}

To investigate the effects of the exhaust dilution on particle emissions, two types of experiments were performed on a chassis dynamometer: 1) dilution and temperature effects on particle emission were investigated with Euro 5 diesel and gasoline vehicles; 2) sampling condition impacts on particle quantification were investigated with Euro 6 diesel and gasoline vehicles. The dilution and temperature effects were studied directly from tailpipe with dilution ratios ranged from 8 to 4000 and dilution temperatures from $50^{\circ} \mathrm{C}$ to $150^{\circ} \mathrm{C}$. Low dilution temperature and low dilution ratios increased the particle number concentration by a factor of 1.4-3. The results highlighted that the low primary dilution ratios induced a significant influence on particle number concentration. At low primary dilution (3-5), the particle emission was 2 times higher than at high primary dilution (12-20). To minimise the bias, the FPS sampling system at tailpipe should be set at high primary dilution and high dilution temperature.

In the second experiment, particle emissions from tailpipe were compared to those after the CVS system under similar dilution conditions with two Euro 6 vehicles (gasoline G-DI and diesel DPFcat). Due to the high efficiency of the diesel particulate filter, PN emissions from the Euro 6 diesel vehicle were near the detection limit. For Euro 6 G-DI vehicle, CVS PN concentrations were higher than those at the tailpipe by a factor of 6, 80 and 22 for Artemis urban, road and motorway, respectively. The main particle size mode after the tailpipe was centred on $10 \mathrm{~nm}$ while, particle size after the CVS was centred at $70 \mathrm{~nm}$ for motorway and $50 \mathrm{~nm}$ for urban and road driving. The increase in PN concentration and the growth of particle size in the CVS were induced by the nucleation and condensation. These processes could be supported by different semi volatile particle precursors observed in our previous studies and by the turbulent flow in the sampling tunnel (Reynolds numbers $=4-5 \times 10^{4}$ ). The coagulation could happen in the CVS because of the high PN concentration and turbulent flow, but it remained a negligible process for the short CVS residence time (2-10s). These results indicated that the CVS sampling system could induce an over-estimation of PN. Particle sampling at tailpipe could represent a complementary method to better quantify the particle emissions.

\section{Acknowledgements}

The authors would like to thank the French Environment and Energy Management Agency (ADEME) for financial support of the CORTEA project CaPVeREA and the Auvergne Rhône-Alpes region. 


\section{References}

Albriet, B., K.N. Sartelet, S. Lacour, B. Carissimo, and C. Seigneur. 'Modelling Aerosol Number Distributions from a Vehicle Exhaust with an Aerosol CFD Model'. Atmospheric Environment 44, no. 8 (March 2010): 1126-37. doi:10.1016/j.atmosenv.2009.11.025.

André, Michel. 'The ARTEMIS European Driving Cycles for Measuring Car Pollutant Emissions.' Science of The Total Environment 334-35 (December 2004): 73-84. doi:10.1016/j.scitotenv.2004.04.070.

Beckers, J., W. W. Stoffels, and G. M. W. Kroesen. 'Temperature Dependence of Nucleation and Growth of Nanoparticles in Low Pressure Ar/CH 4 RF Discharges.' Journal of Physics D: Applied Physics 42, no. 15 (2009): 155206. doi:10.1088/0022-3727/42/15/155206.

Benson, D. R., J. H. Yu, A. Markovich, and S.-H. Lee. 'Ternary Homogeneous Nucleation of H2SO4, NH3, and H2O under Conditions Relevant to the Lower Troposphere.' Atmos. Chem. Phys. 11, no. 10 (20 May 2011): 4755-66. doi:10.5194/acp-11-4755-2011.

Bukowiecki, N., J. Dommen, A. S. H. Prévôt, E. Weingartner, and U. Baltensperger. 'Fine and Ultrafine Particles in the Zürich (Switzerland) Area Measured with a Mobile Laboratory: An Assessment of the Seasonal and Regional Variation throughout a Year.' Atmos. Chem. Phys. 3, no. 5 (24 September 2003): 1477-94. doi:10.5194/acp-3-1477-2003.

Burtscher, H. 'Physical Characterization of Particulate Emissions from Diesel Engines: A Review.' Journal of Aerosol Science 36, no. 7 (July 2005): 896-932. doi:10.1016/j.jaerosci.2004.12.001.

Casati, Roberto, Volker Scheer, Rainer Vogt, and Thorsten Benter. 'Measurement of Nucleation and Soot Mode Particle Emission from a Diesel Passenger Car in Real World and Laboratory in Situ Dilution.' Atmospheric Environment 41, no. 10 (March 2007): 2125-35. doi:10.1016/j.atmosenv.2006.10.078.

Fujitani, Yuji, Katsumi Saitoh, Akihiro Fushimi, Katsuyuki Takahashi, Shuich Hasegawa, Kiyoshi Tanabe, Shinji Kobayashi, Akiko Furuyama, Seishiro Hirano, and Akinori Takami. 'Effect of Isothermal Dilution on Emission Factors of Organic Carbon and N-Alkanes in the Particle and Gas Phases of Diesel Exhaust.' Atmospheric Environment 59 (November 2012): 389-97. doi:10.1016/j.atmosenv.2012.06.010.

Giechaskiel, Barouch, Matti Maricq, Leonidas Ntziachristos, Christos Dardiotis, Xiaoliang Wang, Harald Axmann, Alexander Bergmann, and Wolfgang Schindler. 'Review of Motor Vehicle Particulate Emissions Sampling and Measurement: From Smoke and Filter Mass to Particle Number'. Journal of Aerosol Science 67 (January 2014): 48-86. doi:10.1016/j.jaerosci.2013.09.003.

Giechaskiel, B., R. Chirico, P.F. DeCarlo, M. Clairotte, T. Adam, G. Martini, M.F. Heringa, R. Richter, A.S.H. Prevot, and U. Baltensperger. 'Evaluation of the Particle Measurement Programme (PMP) Protocol to Remove the Vehicles' Exhaust Aerosol Volatile Phase.' Science of The Total Environment 408, no. 21 (1 October 2010): 5106-16. doi:10.1016/j.scitotenv.2010.07.010.

Giechaskiel, Barouch, Panagiota Dilara, and Jon Andersson. 'Particle Measurement Programme (PMP) LightDuty Inter-Laboratory Exercise: Repeatability and Reproducibility of the Particle Number Method'. Aerosol Science and Technology 42, no. 7 (29 May 2008): 528-43. doi:10.1080/02786820802220241.

Giechaskiel, B., L. Ntziachristos, Z. Samaras, and R. Casati. 'Effect of Speed and Speed-Transition on the Formation of Nucleation Mode Particles from a Light Duty Diesel Vehicle', 2007, 15. doi:10.4271/200701-1110.

Grieshop, Andrew P., Marissa A. Miracolo, Neil M. Donahue, and Allen L. Robinson. 'Constraining the Volatility Distribution and Gas-Particle Partitioning of Combustion Aerosols Using Isothermal Dilution and Thermodenuder Measurements.' Environmental Science \& Technology 43, no. 13 (1 July 2009): 4750-56. doi:10.1021/es8032378.

Grieshop, A. P., J. M. Logue, N. M. Donahue, and A. L. Robinson. 'Laboratory Investigation of Photochemical Oxidation of Organic Aerosol from Wood Fires 1: Measurement and Simulation of Organic Aerosol Evolution.' Atmos. Chem. Phys. 9, no. 4 (18 February 2009): 1263-77. doi:10.5194/acp-9-1263-2009.

Huang, L., S. L. Gong, M. Gordon, J. Liggio, R. Staebler, C. A. Stroud, G. Lu, C. Mihele, J. R. Brook, and C. Q. Jia. 'Aerosol-computational Fluid Dynamics Modeling of Ultrafine and Black Carbon Particle Emission, Dilution, and Growth near Roadways.' Atmos. Chem. Phys. 14, no. 23 (2 December 2014): 12631-48. doi:10.5194/acp-14-12631-2014.

Jamriska, Milan, Lidia Morawska, Steven Thomas, and Congrong He. 'Diesel Bus Emissions Measured in a Tunnel Study.' Environmental Science \& Technology 38, no. 24 (1 December 2004): 6701-9. doi:10.1021/es030662z.

Karjalainen, Panu, Liisa Pirjola, Juha Heikkilä, Tero Lähde, Theodoros Tzamkiozis, Leonidas Ntziachristos, Jorma Keskinen, and Topi Rönkkö. 'Exhaust Particles of Modern Gasoline Vehicles: A Laboratory and an on-Road Study.' Atmospheric Environment 97 (November 2014): 262-70. doi:10.1016/j.atmosenv.2014.08.025.

Kim, Youngseob, Karine Sartelet, Christian Seigneur, Aurélie Charron, Jean-Luc Besombes, Jean-Luc Jaffrezo, Nicolas Marchand, and Lucie Polo. 'Effect of Measurement Protocol on Organic Aerosol Measurements 
of Exhaust Emissions from Gasoline and Diesel Vehicles.' Atmospheric Environment 140 (September 2016): 176-87. doi:10.1016/j.atmosenv.2016.05.045.

Kittelson, David B. 'Engines and Nanoparticles : A Review.' Journal of Aerosol Science 29, no. 5/6 (1998): 575-88. doi:0021-8502/98.

Kittelson, David, Jason Johnson, and Winthrop Watts. 'Diesel Aerosol Sampling in the Atmosphere.' San Diego, California, 2000. http://papers.sae.org/2000-01-2212/.

Köhler, Felix. 'Testing of Particulate Emissions from Positive Ignition Vehicles with Direct Fuel Injection System.' Technical Report, 2013-09-26, T\HuV Nord, 2013. http://www.transportenvironment.org/sites/te/files/publications/TUV-Technical_report.pdf.

Kozawa, Kathleen H., Arthur M. Winer, and Scott A. Fruin. 'Ultrafine Particle Size Distributions near Freeways: Effects of Differing Wind Directions on Exposure.' Atmospheric Environment 63 (December 2012): 250-60. doi:10.1016/j.atmosenv.2012.09.045.

Kulkarni, Pramod, Paul A. Baron, and Klaus Willeke. Aerosol Measurement: Principles, Techniques, and Applications. John Wiley \& Sons, 2011.

Kulmala, Markku, Liisa Pirjola, and Jyrki M. Mäkelä. 'Stable Sulphate Clusters as a Source of New Atmospheric Particles.' Nature 404, no. 6773 (2 March 2000): 66-69. doi:10.1038/35003550.

Liang, Bin, Yunshan Ge, Jianwei Tan, Xiukun Han, Liping Gao, Lijun Hao, Wentao Ye, and Peipei Dai. 'Comparison of PM Emissions from a Gasoline Direct Injected (GDI) Vehicle and a Port Fuel Injected (PFI) Vehicle Measured by Electrical Low Pressure Impactor (ELPI) with Two Fuels: Gasoline and M15 Methanol Gasoline.' Journal of Aerosol Science 57 (March 2013): 22-31. doi:10.1016/j.jaerosci.2012.11.008.

Louis, Cédric, Yao Liu, Patrick Tassel, Pascal Perret, Agnès Chaumond, and Michel André. 'PAH, BTEX, Carbonyl Compound, Black-Carbon, NO2 and Ultrafine Particle Dynamometer Bench Emissions for Euro 4 and Euro 5 Diesel and Gasoline Passenger Cars.' Atmospheric Environment 141 (September 2016): 80-95. doi:10.1016/j.atmosenv.2016.06.055.

Mamakos, Athanasios, and Giorgio Martini. 'Particle Number Emissions During Regeneration of DPF-Equipped Light Duty Diesel Vehicles', 2011.

Manoukian, A., D. Buiron, B. Temime-Roussel, H. Wortham, and E. Quivet. 'Measurements of VOC/SVOC Emission Factors from Burning Incenses in an Environmental Test Chamber: Influence of Temperature, Relative Humidity, and Air Exchange Rate.' Environmental Science and Pollution Research 23, no. 7 (April 2016): 6300-6311. doi:10.1007/s11356-015-5819-2.

Mathis, U, M Mohr, and A Forss. 'Comprehensive Particle Characterization of Modern Gasoline and Diesel Passenger Cars at Low Ambient Temperatures.' Atmospheric Environment 39, no. 1 (January 2005): 107-17. doi:10.1016/j.atmosenv.2004.09.029.

Mathis, Urs, Jyrki Ristimäki, Martin Mohr, Jorma Keskinen, Leonidas Ntziachristos, Zissis Samaras, and Pirita Mikkanen. 'Sampling Conditions for the Measurement of Nucleation Mode Particles in the Exhaust of a Diesel Vehicle.' Aerosol Science and Technology 38, no. 12 (January 2004): 1149-60. doi:10.1080/027868290891497.

May, Andrew A., Albert A. Presto, Christopher J. Hennigan, Ngoc T. Nguyen, Timothy D. Gordon, and Allen L. Robinson. 'Gas-Particle Partitioning of Primary Organic Aerosol Emissions: (1) Gasoline Vehicle Exhaust.' Atmospheric Environment 77 (October 2013): 128-39. doi:10.1016/j.atmosenv.2013.04.060.

Morawska, L., Z. Ristovski, E.R. Jayaratne, D.U. Keogh, and X. Ling. 'Ambient Nano and Ultrafine Particles from Motor Vehicle Emissions: Characteristics, Ambient Processing and Implications on Human Exposure.' Atmospheric Environment 42, no. 35 (November 2008): 8113-38. doi:10.1016/j.atmosenv.2008.07.050.

Ning, Zhi. 'Atmospheric Processes Influencing Aerosols Generated by Combustion and the Inference of Their Impact on Public Exposure: A Review.' Aerosol and Air Quality Research, 2010. doi:10.4209/aaqr.2009.05.0036.

Pope III, C. Arden. 'Review: Epidemiological Basis for Particulate Air Pollution Health Standards.' Aerosol Science \& Technology 32, no. 1 (2000): 4-14.

Ranjan, Manish, Albert A. Presto, Andrew A. May, and Allen L. Robinson. 'Temperature Dependence of GasParticle Partitioning of Primary Organic Aerosol Emissions from a Small Diesel Engine.' Aerosol Science and Technology 46, no. 1 (1 January 2012): 13-21. doi:10.1080/02786826.2011.602761.

Rönkkö, Annele Virtanen. 'Effect of Dilution Conditions and Driving Parameters on Nucleation Mode Particles in Diesel Exhaust: Laboratory and on-Road Study.' Atmospheric Environment 40, no. 16 (2006): 28932901. doi:10.1016/j.atmosenv.2006.01.002.

Seinfeld, John H., and Spyros N. Pandis. Atmospheric Chemistry and Physics: From Air Pollution to Climate Change. John Wiley \& Sons, 2016.

Uhrner, Ulrich, Michael Zallinger, Sibylle von Löwis, Hanna Vehkamäki, Birgit Wehner, Frank Stratmann, and Alfred Wiedensohler. 'Volatile Nanoparticle Formation and Growth within a Diluting Diesel Car 
Exhaust.' Journal of the Air \& Waste Management Association 61, no. 4 (April 2011): 399-408. doi:10.3155/1047-3289.61.4.399.

Virtanen, A., T. Rönkkö, J. Kannosto, J. Ristimäki, J. M. Mäkelä, J. Keskinen, T. Pakkanen, R. Hillamo, L. Pirjola, and K. Hämeri. 'Winter and Summer Time Size Distributions and Densities of Traffic-Related Aerosol Particles at a Busy Highway in Helsinki.' Atmospheric Chemistry and Physics 6, no. 9 (2006): 2411-21.

Vouitsis, Elias, Leonidas Ntziachristos, Panayiotis Pistikopoulos, Zissis Samaras, Loukia Chrysikou, Constantini Samara, Chrysi Papadimitriou, Petros Samaras, and George Sakellaropoulos. 'An Investigation on the Physical, Chemical and Ecotoxicological Characteristics of Particulate Matter Emitted from Light-Duty Vehicles.' Environmental Pollution 157, no. 8-9 (August 2009): 2320-27. doi:10.1016/j.envpol.2009.03.028.

Vouitsis, Elias, Leonidas Ntziachristos, and Zissis Samaras. 'Theoretical Investigation of the Nucleation Mode Formation Downstream of Diesel after-Treatment Devices.' Aerosol and Air Quality Research 8, no. 1 (2008): 37-53.

Wang, Yan Jason, and K. Max Zhang. 'Coupled Turbulence and Aerosol Dynamics Modeling of Vehicle Exhaust Plumes Using the CTAG Model.' Atmospheric Environment 59 (November 2012): 284-93. doi:10.1016/j.atmosenv.2012.04.062.

Wei, Wenjuan, Corinne Mandin, Olivier Blanchard, Fabien Mercier, Maud Pelletier, Barbara Le Bot, Philippe Glorennec, and Olivier Ramalho. 'Temperature Dependence of the Particle/gas Partition Coefficient: An Application to Predict Indoor Gas-Phase Concentrations of Semi-Volatile Organic Compounds.' Science of The Total Environment 563-64 (1 September 2016): 506-12. doi:10.1016/j.scitotenv.2016.04.106.

Zhang, K. Max, and Anthony S. Wexler. 'Evolution of Particle Number Distribution near roadways-Part I: Analysis of Aerosol Dynamics and Its Implications for Engine Emission Measurement.' Atmospheric Environment 38, no. 38 (December 2004): 6643-53. doi:10.1016/j.atmosenv.2004.06.043.

Zhang, K.Max, Anthony S. Wexler, Yi Fang Zhu, William C. Hinds, and Constantinos Sioutas. 'Evolution of Particle Number Distribution near Roadways. Part II: The “Road-to-Ambient” Process'. Atmospheric Environment 38, no. 38 (December 2004): 6655-65. doi:10.1016/j.atmosenv.2004.06.044.

Zielinska, Barbara, John Sagebiel, Jacob D. McDonald, Kevin Whitney, and Douglas R. Lawson. 'Emission Rates and Comparative Chemical Composition from Selected in-Use Diesel and Gasoline-Fueled Vehicles.' Journal of the Air \& Waste Management Association 54, no. 9 (2004): 1138-50. 


\section{Appendix}

Table 4. CVS coagulation time for monodisperse particles as function of the PN size and

518 concentration. The coagulation coefficient takes into account the kinetic corrections but not the 519 turbulence.

\begin{tabular}{ccccc}
\hline $\begin{array}{c}\text { Driving } \\
\text { Cycle }\end{array}$ & $\begin{array}{c}\text { PN size } \\
(\mathbf{n m})\end{array}$ & $\begin{array}{c}\text { PN concentration } \\
(\# / \mathbf{c m} \mathbf{)})\end{array}$ & $\begin{array}{c}\text { Coagulation coefficient } \\
(\mathbf{c m} 3 / \mathbf{s})\end{array}$ & $\begin{array}{c}\text { Coagulation time } \\
(\mathbf{s})\end{array}$ \\
\hline \multirow{6}{*}{ Motorway } & 4 & $1.3 \times 10^{6}$ & $1.3 \times 10^{-9}$ & $1.2 \times 10^{3}$ \\
& 10 & $5.5 \times 10^{6}$ & $1.9 \times 10^{-9}$ & $1.9 \times 10^{2}$ \\
& 20 & $1.5 \times 10^{6}$ & $2.4 \times 10^{-9}$ & $5.4 \times 10^{2}$ \\
& 40 & $4.8 \times 10^{3}$ & $2.3 \times 10^{-9}$ & $1.8 \times 10^{5}$ \\
\hline \multirow{6}{*}{ Urban } & 100 & $1.6 \times 10^{3}$ & $1.5 \times 10^{-9}$ & $8.1 \times 10^{5}$ \\
\hline & 4 & $4.4 \times 10^{4}$ & $1.3 \times 10^{-9}$ & $3.5 \times 10^{4}$ \\
& 10 & $1.6 \times 10^{5}$ & $1.9 \times 10^{-9}$ & $6.7 \times 10^{3}$ \\
& 20 & $1.7 \times 10^{4}$ & $2.4 \times 10^{-9}$ & $5.0 \times 10^{4}$ \\
& 40 & $5.2 \times 10^{2}$ & $2.3 \times 10^{-9}$ & $1.7 \times 10^{6}$ \\
Road & 100 & $2.5 \times 10^{2}$ & $1.5 \times 10^{-9}$ & $5.5 \times 10^{6}$ \\
\hline & 4 & $9.7 \times 10^{3}$ & $1.3 \times 10^{-9}$ & $1.6 \times 10^{5}$ \\
& 10 & $1.4 \times 10^{4}$ & $1.9 \times 10^{-9}$ & $7.5 \times 10^{4}$ \\
& 40 & $1.2 \times 10^{4}$ & $2.4 \times 10^{-9}$ & $7.2 \times 10^{4}$ \\
\hline
\end{tabular}

520 


\section{Table of Contents}

\section{Tables}

523 Table 1. Technical characteristics of the tested vehicles.

524 Table 2. Detailed driving cycles with repeated tests number and sampling conditions for the FPS and the CVS with Euro 6 G-DI (No.3) and Euro 6 diesel DPF cat (No.4) vehicles. concentration. The coagulation coefficient takes into account the kinetic corrections but not the

Figures

532 Figure 1. Schema of the experimental setup; the green arrows represent the CVS way and the red arrows represent the direct tailpipe way with FPS dilution.

534 Figure 2. Total dilution and temperature effects (a) and primary dilution and temperature effects (b) 535 for the gasoline Euro 5 vehicle (No. 1) during the motorway driving conditions, at $50^{\circ} \mathrm{C}, 100^{\circ} \mathrm{C}$ and $150^{\circ} \mathrm{C}$. The particle number emissions are corrected taking into account of the dilution factors. For the figure $2 \mathrm{~b}$, the black dots show total dilution ratios at 30, 400, 2000 and 4000 with low primary dilution (3-5) and the white dots show total dilution ratios at 100 and 1000 with high primary dilution (12-20).

540 Figure 3. Particle number concentration of the G-DI vehicle during an Artemis motorway driving 541 cycle, sampled: a) after the tailpipe and b) after the CVS. PN size distribution is described on the left

542 Y-axis. The light blue line represents the vehicle speed $(\mathrm{km} / \mathrm{h})$ on the right $\mathrm{Y}$-axis. 11 Figure 4. Euro 6 G-DI particle size distribution: a) after tailpipe and b) after CVS for Artemis motorway (at 430s), urban (at 500s) and road (at 750s). Data were measured by a Fast Mobility 


\section{Highlights}

- Dilution and temperature effects on particle number emission

- Comparison between tailpipe and CVS for particle number emission

- Over-emission of particles from the CVS because of nucleation, condensation and coagulation

- Tailpipe measurement as a complementary method to the CVS for exhaust particle sampling 